\title{
O EFEITO DA SUPLEMENTAÇÃO COM ÁCIDO LINOLÉICO CONJUGADO SOBRE O PERFIL LIPÍDICO SÉRICO EM RATOS
}

\author{
THE EFFECT OF THE CONJUGATED LINOLEIC ACID \\ SUPPLEMENTATION ON RATS SERUM LIPID PROFILE
}

\author{
Adriana Prais Botelho ${ }^{1}$; Lilia Ferreira Santos-Zago ${ }^{2}$; Soely Maria Pissini Machado Reis ${ }^{3}$; Admar Costa de \\ Oliveira $^{4}$ \\ ${ }^{1}$ State University of Campinas - UNICAMP, Campinas - Brasil abotelho@,fea.unicamp.br \\ ${ }^{2}$ State University of Campinas - UNICAMP, Campinas - Brasil lzago@,fea.unicamp.br \\ ${ }^{3}$ State University of Campinas - UNICAMP, Campinas - Brasil soely@,fea.unicamp.br \\ ${ }^{4}$ State University of Campinas - UNICAMP, Campinas - Brasil admarco@,fea.unicamp.br
}

\begin{abstract}
Resumo
O ácido linoléico conjugado (CLA), um conjunto de isômeros geométricos e de posição do ácido linoléico, vem sendo muito estudado devido aos seus efeitos benéficos em relação à saúde. $O$ objetivo deste trabalho foi avaliar o efeito da suplementação com ácido linoléico conjugado sobre o perfil lipídico de ratos Wistar saudáveis em crescimento. Um total de 40 ratos, divididos em 4

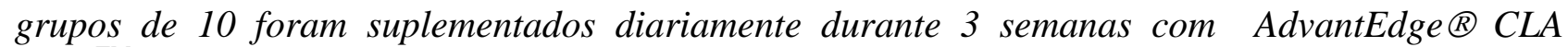
$\left(E A S^{T M}\right)$ nas concentrações $1 \%, 2 \%$ e $4 \%$ sobre o consumo diário de dieta, constituindo respectivamente os grupos AE1, AE2 e AE4, e com ácido linoléico na concentração de 2\% sobre o consumo diário de dieta, constituindo o grupo controle $(C)$. Os animais foram suplementados por meio de entubação orogástrica. Para a avaliação do perfil lipídico, o sangue dos animais foi coletado sob anestesia após jejum de 12 horas e a determinação dos triacilgliceróis e colesterol total séricos realizada com a utilização de kits enzimáticos. Não houve diferença estatística entre os teores de triacilgliceróis $(p \leq 0,05)$. Quanto aos valores de colesterol total, o grupo AE1 apresentou um teor superior ao grupo controle, ocorrendo uma redução dos valores à medida que aumentava a quantidade suplementada de CLA.
\end{abstract}

Palavras-chaves: ácido linoléico conjugado; suplementação; perfil lipídico sérico; ratos.

\section{Introdução}

O ácido linoléico conjugado (CLA), corresponde a uma mistura de isômeros de posição e geométricos com duplas ligações conjugadas do ácido octadecadienóico (C18:2), é encontrado em pequenas quantidades em uma grande variedade de alimentos e estima-se a existência de 56 possíveis isômeros (CHOUIRNAD; BAUMAN; BAUMGARD, 1999). O CLA pode ser originado de forma endógena no rúmen, por meio da biohidrogenação incompleta de ácidos graxos poliinsaturados provenientes da dieta e também, pela dessaturação do ácido graxo C18:1 trans-11. 
Na biohidrogenação, o isômero cis-9, trans-11 é o primeiro intermediário formado a partir do ácido linoléico pela $\Delta^{12}$ e $\Delta^{11}$ trans-isomerase. Em seguida, ocorrem reduções das ligações cis, até C18:1 trans-11, que podem ainda ser reduzidas até C18:0 (CHOUIRNAD; BAUMAN; BAUMGARD, 1999; YURAWECZ et al., 1999). Na outra via de produção do CLA o ácido graxo C18:1 trans-11 sofre dessaturação pela enzima $\Delta^{9}$ dessaturase presente na glândula mamária e no tecido adiposo (CORL et al., 2000). Sendo assim concentrações significativas de CLA podem ser encontradas nas carnes, no leite e seus produtos derivados (PARODI, 1977; SANDRES et al., 2004). Inúmeros trabalhos têm demonstrado efeitos benéficos relacionados à saúde com a utilização do CLA. Estes efeitos incluem: anticarcinogênese, redução da aterosclerose, alterações na composição corporal, modulação do sistema imune e potencialização da mineralização óssea (WAHLE; HEYS; ROTONDO, 2004). Possíveis efeitos adversos como aumento da suscetibilidade à autoxidação lipídica também foram observados (GRIINARI et al., 2000; YAMASAKI et al., 2000).

O consumo de CLA tem demonstrado efeito sobre o perfil lipídico e antiaterogênico em diferentes modelos experimentais, como coelhos (LEE; KRITCHEVSKY; PARIZA, 1994), camundongos (MUNDAY; THOMPSON; JAMES, 1999), ratos (RAHMAN et al., 2001), entre outros. Este efeito pode ser explicado pelo declínio da produção de colesterol, assim como de sua secreção pelo fígado (SAKONO et al., 1999), pela redução da síntese de triacilgliceróis, associada ao aumento de sua oxidação e maior ativação do PPAR (RAHMAN et al., 2001) e também inibição da produção de tromboxano e conseqüente diminuição da agregação plaquetária (TRUITT; MCNEILL; VADERHOEK, 1999). Pelo fato do CLA mostrar-se efetivo sobre as alterações no perfil lipídico em alguns modelos experimentais, novos trabalhos precisam ser realizados com o propósito de elucidar os mecanismos de ação do CLA na prevenção da aterosclerose e dessa maneira assegurar sua utilização na redução das doenças cardiovasculares em humanos (BELURY, 2002). Dessa maneira, o objetivo deste trabalho foi avaliar o efeito da suplementação com misturas comerciais de ácido linoléico conjugado sobre o perfil lipídico de ratos Wistar saudáveis em crescimento.

\section{Material e métodos}

Foram utilizados 40 ratos Wistar, albinos, machos, saudáveis, recém desmamados (21 a 23 dias), com peso médio de 52,4 \pm 4,34 g, provenientes do Centro Multidisciplinar de Investigação Biológica (CEMIB/UNICAMP). Durante todo o período experimental os animais permaneceram em gaiolas de crescimento individuais consumindo água e dieta AIN93G (REEVES et al., 1993) com concentração de proteína de 12\% (GOENA et al., 1989) sob o sistema de livre acesso, sendo a temperatura e a umidade do ar controladas na faixa de $22 \pm 1{ }^{\circ} \mathrm{C}$ e $60-70 \%$ respectivamente e ciclo 
de claro/escuro de 12 horas. Após um período de 7 dias de adaptação, os ratos foram divididos aleatoriamente em 4 grupos de 10 animais cada (controle e experimentais) e suplementados por 21 dias. O acompanhamento do ganho de peso assim como o consumo de dieta foi realizado a cada dois dias. Os grupos receberam ácido linoléico conjugado AdvantEdge ${ }^{\circledR}$ CLA $\left(\mathrm{EAS}^{\mathrm{TM}}\right)$ nas concentrações $1 \%, 2 \%$ e $4 \%$ sobre o consumo diário de dieta, constituindo respectivamente os grupos AE1, AE2 e AE4 (experimentais), e com ácido linoléico na concentração de 2\% sobre o consumo diário de dieta, constituindo o grupo $\mathrm{C}$ (controle). A suplementação foi realizada diariamente por meio de entubação orogástrica utilizando seringas descartáveis de $1 \mathrm{~mL}$ e agulhas de gavagem. A quantidade de suplemento administrada era calculada a cada dois dias com base no consumo médio diário de dieta de cada grupo. Sendo assim, a suplementação acompanhou a ingestão de dieta normal dos ratos. Levou-se em consideração a densidade de cada suplemento para o cálculo da quantidade em mililitros, que variou de 0,11 a $0,58 \mathrm{~mL}$. Ao final do experimento o sangue dos animais foi coletado sob anestesia (pentobarbital sódico), por meio de punção cardíaca após jejum de 12 horas. As amostras de sangue foram depositadas em tubos sem anticoagulante, que por sua vez, repousaram em banho-maria a $37^{\circ} \mathrm{C}$ por 30 minutos e, em seguida, foram centrifugados a $3000 \mathrm{rpm}$ por 10 minutos (CARVALHO, 1999). Posteriormente, o soro foi armazenado a $-80^{\circ} \mathrm{C}$ até o momento das análises. As determinações de triacilgliceróis e colesterol total séricos foram feitas até 12 horas após a coleta utilizando-se kits enzimáticos Labtest Diagnóstica códigos GPO-ANA-CAT. 59 e COD-ANA-CAT. 60, respectivamente.

Os dados foram submetidos à análise de variância ANOVA, seguida de teste de Tukey, com nível de significância de 5\%. O software utilizado para a análise foi o Statistical Analysis System (SAS) (SAS, 1993).

\section{Resultados e discussão}

As doenças cardiovasculares são as principais causas de morbi-mortalidade nos países desenvolvidos e em grande parte dos países em desenvolvimento. Embora o mecanismo de surgimento da aterosclerose seja controverso, sabe-se que a hipertrigliceridemia e a hipercolesterolemia são fatores importantes para seu aparecimento (LIBBY, 2002; LAMARCHE e DESROCHES, 2004).

Os teores de triacilgliceróis séricos $(\mathrm{mg} / \mathrm{dL})$ apresentados na Tabelas 1 não apresentam diferença estatisticamente significante $(\mathrm{p}>0,05)$. Da mesma maneira, não foram observadas diferenças nos teores de triacilgliceróis séricos em ratos Sprague-Dawley suplementados com 0,25 e 0,5\% de CLA durante 5 semanas (AZAIN et al., 2000). Resultados similares foram encontrados quando ratos receberam óleo de soja hidrogenado rico em CLA. Após 6 semanas de experimentação 
os animais suplementados com 1,5 e 5\% obtiveram valores de triacilgliceróis séricos iguais ao grupo controle (CHOI et al., 2004).

Com relação aos teores de colesterol total $(\mathrm{mg} / \mathrm{dL})$, apenas o grupo AE1 apresentou valor superior ao grupo controle, ocorrendo uma redução destes valores à medida que aumentava a quantidade de CLA suplementada. Estes resultados sugerem que durante um curto período de suplementação, como 21 dias, o CLA parece exercer um efeito dose dependente inverso. Estes resultados mostram-se semelhantes à estudos anteriores em que a suplementação com CLA reduziu os níveis séricos de colesterol total (CHOI et al., 2004; FAULCONNIER et al., 2004), confirmando seu efeito antiaterogênico.

Tabela 1. Valores médios \pm desvio padrão $(n=10)$ de triacilglicerol e colesterol total séricos dos grupos controle e experimentais.

\begin{tabular}{ccc}
\hline Grupos & $\begin{array}{c}\text { Triacilgliceróis } \\
(\mathrm{mg} / \mathrm{dL})\end{array}$ & $\begin{array}{c}\text { Colesterol total } \\
(\mathrm{mg} / \mathrm{dL})\end{array}$ \\
\hline C & $116,25 \pm 37,95^{\mathrm{a}}$ & $90,63 \pm 7,85^{\mathrm{a}}$ \\
AE1 & $118,76 \pm 39,07^{\mathrm{a}}$ & $105,44 \pm 11,24^{\mathrm{b}}$ \\
AE2 & $117,65 \pm 58,18^{\mathrm{a}}$ & $95,02 \pm 14,30^{\mathrm{a}}$ \\
AE4 & $97,08 \pm 34,00^{\mathrm{a}}$ & $74,96 \pm 6,80^{\mathrm{c}}$ \\
\hline
\end{tabular}

Valores com letras iguais na mesma coluna não apresentam diferença significativa $(\mathrm{p}>0,05)$ ao teste de Tukey.

Vale destacar que grande parte dos estudos que procuram investigar a ação do CLA sobre o perfil lipídico, utilizam modelos experimentais e dietas pró-aterogênicos. Dessa maneira, o efeito da suplementação torna-se mais evidente, como o estudo realizado com coelhos, em que os animais foram suplementados com CLA (0,5g/coelho/dia) adicionado a uma dieta hipercolesterolêmica por 22 semanas. Após este período houve uma redução significativa $(\mathrm{p}<0,02)$ da fração LDL colesterol dos grupos experimentais, quando comparados ao grupo controle (LEE; KRITCHEVSKY; PARIZA, 1994). No mesmo sentido, camundongos "knockout" para apo E suplementados com 1\% de CLA apresentaram um retardo no desenvolvimento da aterosclerose, assim como regressão no tamanho das lesões já existentes (TOOMEY et al., 2003). Também é importante considerar evidências de que o isômero trans-10, cis-12 seja o responsável pelo efeito antiaterogênico observado em estudos que utilizam CLA (DECKERE et al., 1999; FAULCONNIER et al., 2004; STANGL, 2000) e que em nosso estudo foram utilizadas misturas de isômeros de CLA, que aparentemente exercem menos efeito sobre o perfil lipídico. 


\title{
4. Conclusões
}

Sob as condições experimentais deste estudo, o CLA não exerceu efeito sobre os teores de triacilgliceróis séricos. No entanto os teores de colesterol total séricos apresentaram uma redução à medida que aumentava a quantidade de CLA suplementada, o que aparece como uma contribuição ao estudo da ação do CLA na prevenção da aterosclerose.

\begin{abstract}
The conjugated linoleic acid (CLA), a group of positional and geometric isomers of linoleic acid, has been investigated because of its effect related to the health. The purpose of this study was evaluate the effect of conjugated linoleic acid supplementation on the healthy growing Wistar rats lipid profile. Fourty male Wistar rats were divided in 4 groups of 10 and supplemented daily during 3 weeks with $1 \%, 2 \%$ and $4 \%$ of AdvantEdge ${ }^{\circledR}$ CLA $\left(\mathrm{EAS}^{\mathrm{TM}}\right)$ in relation to the daily feed intake, corresponding to groups AE1, AE2 and AE4, and with linoleic acid at 2\% (control) corresponding to the group $\mathrm{C}$. The animals were supplemented via a stomach tube. To analyse the lipid profile, the blood of the animals was collected under anesthesia after fasted 12 hours and the serum triacylglycerols and total cholesterol were determined by enzymatics assays. No significant difference was noted in triacylglycerols values $(\mathrm{p} \leq 0,05)$. Related to total cholesterol values, group AE1 presented a higher text in relation to control group, showing a reduction of the values the measure that increased the supplemented amount of CLA.
\end{abstract}

Keywords: conjugated linoleic acid; supplementation; serum lipid profile; rats.

\section{Referências}

AZAIN, M. J.; HAUSMAN, D. B.; SISK, M. B.; FLATT, W. P.; JEWELL, D. E. Dietary conjugated linoleic acid reduces rat adipose tissue cell size rather than cell number. The Journal of Nutrition, v. 130, n. 6, p. 1548-1554, 2000.

BELURY, M. A. Dietary conjugated linoleic acid in health: physiological effects and mechanismis of action. Annual Review of Nutrition, v. 22, p. 505-531, 2002.

CARVALHO, W.F. Técnicas médicas de hematologia e imuno-hematologia. 7 ed. Belo Horizonte: Coopmed, 1999. 340 .

CHOI, N.; KWON, D.; YUN, S.H.; JUNG, M.Y.; SHIN, H. Selectively hydrogenated soybean oil with conjugated linoleic acid modifies body composition and plasma lipids in rats. Journal of Nutritional Biochemistry, v. 15, p. 411417, 2004.

CHOUINARD, P. Y.; BAUMAN, B. A.; BAUMGARD, M. A. An update on conjugated linoleic acid. In: CORNELL NUTRITION CONFERENCE FEED MANUFACTORY, 1999, Ithaca. Procceedings. Ithaca: Cornell University, 1999, p. 93-101.

CORL, B. A.; BAUMGARD, L. H.; PARIZA, M. W. Derivatives of conjugated linoleic acid (CLA) and fat reduction. The FASEB Journal, v. 14, n. 4, A525-A525, 2000. Abstract 366.8.

DECKERE, E. A. M. de; AMELSVOORT, J. M. M. V.; MCNEILL, G. P.; JONES, P. Effects of conjugated linoleic acid (CLA) isomers on lipid levels and peroxisome proliferation in the hamster. British Journal of Nutrition, v. 82, p. 309-317, 1999.

FAULCONNIER, Y.; ARNAL, M.; MIRAND, P.P.; CHARDIGNY, J.; CHILLIARD, Y. Isomers of conjugated linoleic acid decrease plasma lipids and stimulate adipose tissue lipogenesis without changing adipose weight in postprandial adult sedentary or trained Wistar rat. Journal of Nutritional Biochemistry, v. 15, p. 741-748, 2004. 
GOENA, M.; MARZO, F.; FERNÁNDEZ-GONZÁLEZ, L.; TOSAR, A.; FRÜHBECK, G.; SANTIDRIÁN, S. Effect of the raw legume Vicia ervilha on muscle and liver protein metabolism in growing rats. Revista Española de Fisiologia, Pamplona, v. 45, p. 55-60, 1989. Suplemento.

GRIINARI, J. M.; CORL, B. A.; LACY, S. H.; CHOUINARD, P. Y.; NURMELA, K. V. V.; BAUMAN, D. E. Conjugated linoleic acid is synthesized endogenously in lactating dairy cows by $\Delta^{9}$ desaturase. The Journal of Nutrition, v. 130, n. 9, p. 2285-2291, 2000.

LAMARCHE, B. e DESROCHES, S. Metabolic syndrome and effects of conjugated linoleic acid in obesity and lipoprotein disorders: the Québec experience. American Journal of Clinical Nutrition, v. 79, p. 1149S-1152S, 2004.

LEE, K. N.; KRITCHEVSKY, D.; PARIZA, M. W. Conjugated linoleic acid and atherosclerosis in rabbits. Atherosclerosis, v. 108, p. 19-25, 1994.

LIBBY, P. Atherosclerosis: the new view. Scientific American, v. 286, n. 5, p. 29-37, 2002.

MUNDAY, J. S.; THOMPSON, K. G.; JAMES, K. A. Dietary conjugated linoleic acids promote fatty streak formation in the C57BL/6 mouse atherosclerosis model. British Journal of Nutrition, v. 81, p. 251-255, 1999.

PARODI, P. W. Conjugated octadecadienoic acids of milk fat. Journal of Dairy Science, v. 60, n. 5, p. 1550-1553, May, 1977.

RAHMAN, S. M.; WANG, Y. M.; YOTSUMOTO, H.; CHA, J. Y.; HAN, S. Y.; INOUE, S.; YANAGITA, T. Effects of conjugated linoleic acid on serum leptin concentration, body-fat accumulation, and $\beta$-oxidation of fatty acid in OLETF rats. Nutrition, v. 17, p. 385-390, 2001.

REEVES, P. G.; NIELSEN, F. H.; FAHEY, G. C. Jr. AIN-93 Purified diets for laboratory rodents: final report of the American Institute of Nutrition Ad Hoc Writing Committee on the Reformulation of the AIN-76A rodent diet. Journal of Nutrition, v. 123, p. 1939-1951, 1993.

SAKONO, M.; MIYANAGA, F.; KAWAHARA, S.; YAMAUCHI, K.; FUKUDA, N.; WATANABE, K.; IWATA, T.; SUGANO, S. Dietary conjugated linoleic acid reciprocally modifies ketogenesis and lipid secretion by rat liver. Lipids, v. 34, p. 997-1000, 1999.

SANDRES, S.R.; TEACHEY, M.K.; PTOCK, A.; KRAEMER, K.; HASSELWANDER, O.; HENRIKSEN, E.J.; BAUMGARD, L.H. Effects os specific conjugated linoleic acid isomers on growth characteristics in obese Zucker rats. Lipids, v. 39, p. 537-543, 2004.

STANGL, G. I. Conjugated linoleic acids exhibit a strong fat-to-lean partitioning effect reduce serum VLDL lipids and redistribute tissue lipids in food-restricted rats. The Journal of Nutrition, v. 130, n. 5, p. 1140-1146, 2000.

TOOMEY, S.; ROCHET, H.; FITZGERALD, D.; BELTON, O. Regression of pre-established atherosclerosis in the $\operatorname{apoE}^{-/}$mouse by conjugated linoleic acid. Biochemical Society Transactions, v. 31, p. 1075-1079,.2003.

TRUITT, A.; MCNEILL, G.; VANDERHOEK, J. Y. Antiplatelet effect of conjugated linoleic acid isomers. Biochimica et Biophysica Acta, v. 1438, p. 239-246, 1999.

WAHLE, K. W. J.; HEYS, S. D.; ROTONDO, D. Conjugated linoleic acid: are they beneficial or detrimental to health? Progress in Lipid Research, v. 43, p. 553-587, 2004.

YAMASAKI, M.; KISHIHARA, K.; MANSHO, K.; OGINO, Y.; KASAI, M.; SUGANO, M.; TACHIBANA, H.; YAMADA, K. Dietary conjugated linoleic acid increases immunoglobulin productivity of Sprague-Dawley rat spleen lymphocytes. Bioscience, Biotechnology and Biochemistry, v. 64, n. 10, p. 2159-2164, 2000.

YURAWECZ, M. P.; SEHAT, N., MOSSOBA, M. M; ROACH, J. A. G.; KRAMER, J. K. G.; KU, Y. Variations in isomer distribution in commercially available conjugated linoleic acid. Fett/Lipid, v. 101, n. 7, p. $277-282,1999$. 


\section{Agradecimentos}

A Fundação de Amparo à Pesquisa do Estado de São Paulo pelo auxílio financeiro (Processo $n^{\circ}$ 03/07648-4) e ao Conselho Nacional de Desenvolvimento Científico e Tecnológico pela bolsa concedida (APB) (Processo n $\left.{ }^{\circ} 133874 / 2003-6\right)$

Nome completo: Adriana Prais Botelho

Filiação institucional: Faculdade de Engenharia de Alimentos / Universidade Estadual de Campinas Departamento: Departamento de Alimentos e Nutrição

Função ou cargo ocupado: Aluna do Curso de Doutorado em Alimentos e Nutrição

Endereço completo para correspondência: Rua Monteiro Lobato, 80 - Cidade Universitária “Zeferino Vaz", Campinas, SP, Brasil, CEP 13083-862

Telefones para contato: (19) 3232-4829 / (19) 3521-4068

Email: abotelho@,fea.unicamp.br

Nome completo: Lilia Zago Ferreira dos Santos

Filiação institucional: Faculdade de Engenharia de Alimentos / Universidade Estadual de Campinas

Departamento: Departamento de Alimentos e Nutrição

Função ou cargo ocupado: Aluna do Curso de Doutorado em Alimentos e Nutrição

Endereço completo para correspondência: Rua Monteiro Lobato, 80 - Cidade Universitária “Zeferino Vaz", Campinas, SP, Brasil, CEP 13083-862

Telefones para contato: (19) 3867-1584 / (19) 3521-4068

Email: $\underline{\text { lzago@,fea.unicamp.br }}$

Nome completo: Soely Maria Pissini Machado Reis

Filiação institucional: Faculdade de Engenharia de Alimentos / Universidade Estadual de Campinas

Departamento: Departamento de Alimentos e Nutrição

Função ou cargo ocupado: Bióloga Técnica de Apoio ao Ensino e à Pesquisa do Laboratório de Lípides

Endereço completo para correspondência: Rua Monteiro Lobato, 80 - Cidade Universitária “Zeferino Vaz", Campinas, SP, Brasil, CEP 13083-862

Telefones para contato: (19) 3521-4068

Email: soely@fea.unicamp.br

Nome completo: Admar Costa de Oliveira

Filiação institucional: Faculdade de Engenharia de Alimentos / Universidade Estadual de Campinas

Departamento: Departamento de Alimentos e Nutrição

Função ou cargo ocupado: Professor Doutor Associado MS-5

Endereço completo para correspondência: Rua Monteiro Lobato, 80 - Cidade Universitária “Zeferino Vaz", Campinas, SP, Brasil, CEP 13083-862

Telefones para contato: (19) 3521-4077 / (19) 3521-4068

Email: admarco@fea.unicamp.br 